\title{
Chapter 20 \\ Art and Innovation at International Health Promotion Conferences
}

\author{
Christa Ayele, J. Hope Corbin, Emily Alden Hennessy, \\ Mariana Sanmartino, and Helga Bjørnøy Urke
}

\section{1 (Re)Thinking the Dynamics of International Conferences}

The first international scientific conferences were held in the mid-1800s; since then around 170,000 conferences have followed, and they now occupy a ubiquitous presence in all scientific fields (SciConf 2019). SciConf, a research group in Sweden formed to study conferences, suggests that they are worthy of critical inquiry. The group poses questions such as: "What happens at scientific conferences? How have they exchanged knowledge and shaped expertise? What forms of sociability have

\footnotetext{
C. Ayele

International Union for Health Promotion and Education's Student and Early Career Network, Philadelphia, PA, USA

e-mail: christaamayele@gmail.com

\section{J. H. Corbin}

Department of Health and Community Studies, Western Washington University,

Bellingham, WA, USA

e-mail: hope.corbin@wwu.edu

E. A. Hennessy

Department of Psychology, Institute for Collaboration on Health, Intervention \& Policy,

University of Connecticut, Storrs, CT, USA

e-mail: ehennessy@mgh.harvard.edu

M. Sanmartino

Grupo de Didáctica de las Ciencias, IFLYSIB, CONICET - UNLP. Grupo ¿De qué hablamos cuando hablamos de Chagas?, La Plata, Buenos Aires, Argentina

e-mail: mariana.sanmartino@conicet.gov.ar

H. B. Urke $(\square)$

Department of Health Promotion and Development, Faculty of Psychology, University of

Bergen, Bergen, Norway

e-mail: helga.urke@uib.no
} 
developed in these meetings, what rituals have been performed? How have scientific conferences embodied social hierarchies and international relations? How have they informed policies on relevant subjects?" (SciConf 2019). This recognition of conferences as important formal structures that embody social hierarchies and conform to accepted practices is important to examine, particularly in a field like health promotion, which is concerned with participation, collaboration, and equity (for more background on this issue, see Chap. 1, this volume).

Most traditional scientific conferences, including in the health promotion field, have a fairly predictable structure to their scientific programs. The central daily feature is usually one or two keynote speakers that each give a lecture on a topic of their expertise. These lectures typically range from 20-45 minutes, and sometimes there will be time for questions in the end. Parallel panel sessions are another common component of traditional scientific conferences, where a number of researchers present work on related topics. Usually three to five presenters are allocated 10-15 minutes to present, and again, there may be a bit of time at the end for questions from the audience depending on the speakers' adherence to their time guidelines and the militancy of the session chair/timekeeper. Poster presentations are another popular session type that typically involve a room of hanging posters that are each attended by their author, which should enable conference participants to engage in conversation with poster authors about their research (although this exchange does not always take place). Other conference activities include roundtable discussions, symposia, and workshops, which may or may not involve deeper engagement than the session types described above.

From a pedagogical perspective, the conference structure described above adheres almost entirely to Freire's "banking" concept of education (Freire 1970). That is, the presenter-whether speaking at a keynote, panel session, or poster presentation-is the "expert" who is "depositing" knowledge, while the audience is relegated to "receiving, filing and storing the deposits" (Freire 1970, p. 53). This vertical education approach and non-dialogic dynamic is a feature of traditional Western/Northern education systems (Tikly 2004). Boaventura de Sousa Santos (2016) describes the ubiquity of this educational approach in the notion of the monoculture of knowledge, which describes how hegemonic, modern notions of science and high culture are turned into the only criteria upon which all others' ways of thinking and creative expressions are judged (de Sousa Santos 2016). As a result, approaches not recognized by this monoculture are essentially ignored or assumed non-existent. Chilisa (2005) brings the limitations of these models - and indeed the dominance of the Western/Northern way of knowing-into stark light in the arena of health promotion by acknowledging that the knowledge and health promotion programs produced in this manner risk the lives of people in the Global South because of a lack of cultural relevance and honest engagement with multiple ways of knowing (for more background on this issue, see Chap. 21, this volume).

The scientific conference serves as a forum in which new ideas can be presented to a knowledgeable and critical audience and where findings and methods can be debated and discussed and networks can be built for future collaborations (Simkhada et al. 2013). However, when much of the conference program is characterized by a presenter and his/her/their audience engaging in one-way communication, several of these aims have limited potential of being fulfilled through the formal program. 
The informal program (coffee breaks, lunchtime, social events) can, of course, be a more suitable arena for the interaction. However, there may be undiscovered/unexplored potential for more fruitful interaction in the formal agenda.

Luckily, more and more examples of scientific events that seek to break with this classic scheme can be found, promoting spaces of more authentic exchange and less "scientificism" (Varsavsky 1969). Such is the case, for example, in the events promoted by the Latin American and Caribbean Network for the Popularization of Science and Technology (RedPoP) or the so-called unconferences, which are meetings that place less emphasis on formal speeches and presentations and devote more time and focus to discussions and connections between researchers/participants, applying a range of participatory methods for the exchange of knowledge (Zimmer et al. 2011). In order for academic conferences to fulfill their potential as true spaces of collaboration, critical reflection, exchange, and ultimately liberatory educational experiences (Tikly 2004), we argue that innovations are required that transcend formal structures, language barriers, and rigid ways of knowing.

\subsection{The Contribution of Arts-based Approaches}

Arts-based approaches have been used as vehicles for understanding in various contexts. Graham (1995) argued that art is a medium that can be used for education to "develop the mind and promote understanding" (p. 28). For example, while teaching adult nursing students, Nguyen et al. (2016) found that students who used art to dialog were able to communicate experiences that words would not adequately convey. Furthermore, they argued that art inspired "emotion, personal awareness, and exploration" (Nguyen et al. 2016, p. 408). Fox et al. (2016) utilized themes from the popular fictional story "Alice in Wonderland" to facilitate discussions concerning the challenges and strategies of professional collaboration. These authors found that their method introduced participants to new pathways of learning as well as inspired self-awareness and confidence on personal levels (Fox et al. 2016). These personal outcomes were a result of the arts-based approach but also worked to support shared interactions and the insights with others.

Arts-based approaches are naturally multidimensional; in contrast to conventional methods of understanding, in these approaches, validation exists beyond the dichotomy of right or wrong. Eernstman et al. (2012) explains that within art several paths of understanding can be explored, and that the need to make a decision based on correctness is not as dire as with other subjects. The space that art creates for multiple truths to coexist is, arguably, one of the most significant characteristics of utilizing an arts-based approach. For these reasons, we consider such approaches to be a fertile arena to promote an Ecology of Knowledges - an alternative to address the monoculture of modern science (de Sousa Santos 2012; Chap. 12, this volume). The ecology of knowledges assumes that all interactions between human beings and nature involve multiple manifestations of knowledge (de Sousa Santos 2012). Within this framework, and from the critical view that we have been proposing, we argue that for a field like health promotion, arts-based conference presentations 
should be intentionally incorporated, as they could respect and invite reflection on different forms of knowledge, thus better reflecting the participatory and social justice intentions of health promotion (WHO 1986; Chap. 1, this volume).

In this chapter, we provide an example of how the Student and Early Career Network of the International Union for Health Promotion and Education (ISECN) found an innovative and dialogical way of breaking with the classic model of the scientific conference by incorporating art in multiple sessions at international health promotion conferences.

\subsection{The International Union for Health Promotion and Education's (IUHPE) Student and Early Career Network (ISECN) and Their Conference Sessions}

The ISECN was founded in 2006 to create a space for students and early career professionals interested in pursuing a community within the larger IUHPE global network. The purpose of ISECN, while constantly evolving, is to unify great minds, bridge research interests, and inspire action that positively influences the world (Corbin et al. 2012). Global networks, as such, encourage the cross-cultural partnerships that continuously diversify our knowledge base. To deepen connections within the network and to contribute to the field of health promotion, ISECN from its inception worked to plan conference sessions at the IUHPE's conferences. The use of art as a medium for communication for an ISECN conference session was first raised during the planning for the ISECN's participation in the 5th IUHPE regional Latin-American conference in Mexico City in 2012.

The decision to include art-based presentations began as an entirely pragmatic decision. In planning for this conference in Mexico, we were faced with a practical problem: how can a group of people who all speak different languages successfully organize and conduct a session for a largely Spanish-speaking audience, without the possibility for simultaneous translation? And, how could we do so in a way that resulted in synergy among conference attendees (see Chap. 21, this volume)? The answer to these questions resulted in the inspiring and foundational idea that became the title of our first session on arts and health promotion: "How to speak about health without words?"

\subsubsection{Speaking About Health Without Words: Mexico City, Mexico, 2012}

The session (90-minutes) incorporated three key strands: arts-based research and practice projects being conducted by ISECN members, original artistic contributions created particularly for the session by ISECN members, and finally an interactive mural activity facilitated by professional artists from Mexico City. 
Table 20.1 Arts-based research and practice presented in Mexico City, Mexico

\begin{tabular}{l|l|l|l}
\hline Title/Topic & Art Form & Author/Presenter & Country \\
\hline $\begin{array}{l}\text { Mental Health Problems \& } \\
\text { Substance Abuse Among Women }\end{array}$ & $\begin{array}{l}\text { Photos taken by women in a } \\
\text { photovoice project }\end{array}$ & Hilary McGregor & Canada \\
\hline $\begin{array}{l}\text { Child-led Households and } \\
\begin{array}{l}\text { Children with Caretaker } \\
\text { Responsibilities due to HIV/AIDS } \\
\text { in Africa }\end{array}\end{array}$ & $\begin{array}{l}\text { Reproductions of } \\
\text { photography and drawings } \\
\text { made by children }\end{array}$ & Morten Skoval & Kenya \\
\hline $\begin{array}{l}\text { Combination of Contributions } \\
\text { from Art and Science to } \\
\begin{array}{l}\text { Communicate About Chagas } \\
\text { Disease }\end{array}\end{array}$ & $\begin{array}{l}\text { Projections of painting from } \\
\text { series CHAGAS by artist } \\
\text { Néstor Favre-Mossier }\end{array}$ & $\begin{array}{l}\text { Mariana } \\
\text { Sanmartino }\end{array}$ & Argentina \\
\hline $\begin{array}{l}\text { Illustrating Chagas Disease } \\
\text { Projections of drawings } \\
\text { illustrated by Mexican } \\
\text { children }\end{array}$ & $\begin{array}{l}\text { Janine Ramsey } \\
\text { and Alba Valdez } \\
\text { Tah }\end{array}$ & Mexico \\
\hline
\end{tabular}

The first 45 minutes of the session were set up as a "gallery walk" with art pieces displayed around the room. We played songs with health promotion themes and allowed participants to wander the room looking at the various presentations. The presentations of research and practice initiatives (see Table 20.1) consisted of a photovoice project on the topic of mental health and substance use in Canada, photography and drawings created by children with caretaker responsibilities in childheaded households in Kenya, and paintings on the topic of Chagas disease produced by both a professional artist (from Argentina) and by children (from Mexico).

During the gallery walk, participants also had the opportunity to view and listen to materials created by ISECN members for this session to answer the following question: "What helps me be healthy?" The visual displays consisted of drawings and paintings that were collected from children ranging in age from 3-12 years. ISECN members went to local schools in Puerto Rico, Norway, Argentina, and the U.S. and asked children to reflect on the aforementioned question with drawings or paintings. The illustrations were placed all over the venue for participants to enjoy and consider.

Before the conference, ISECN members were asked to record sounds in answer to that same question (Fig. 20.1), through which we obtained sounds such as a smoothie being slurped through a straw, the deep breathing of someone exercising, and children singing. These sounds were artfully combined and edited by Alejandro Valencia-Tobón (Colombia), and during the session, a computer was set up at a table in the middle of the room with headphones to allow participants to listen to the compilation. Pads of blank sticky notes were provided, and participants were asked to reflect on what they were hearing using a word or phrase in their language.

The final 45 minutes of the session were devoted to the co-creation of a mural. Prior to the meeting, ISECN members connected with a local artist group, Cultura Colectiva, to create a mural depicting ideas directly related to the prompt of the session. The concept for the mural was to create a garden with all of the participants contributing a plant, flower, animal, or some other element. The activity was meant to be accessible for people of all artistic levels. By providing many materials, participants had the ability to paint or collage or draw-whatever felt most comfortable 


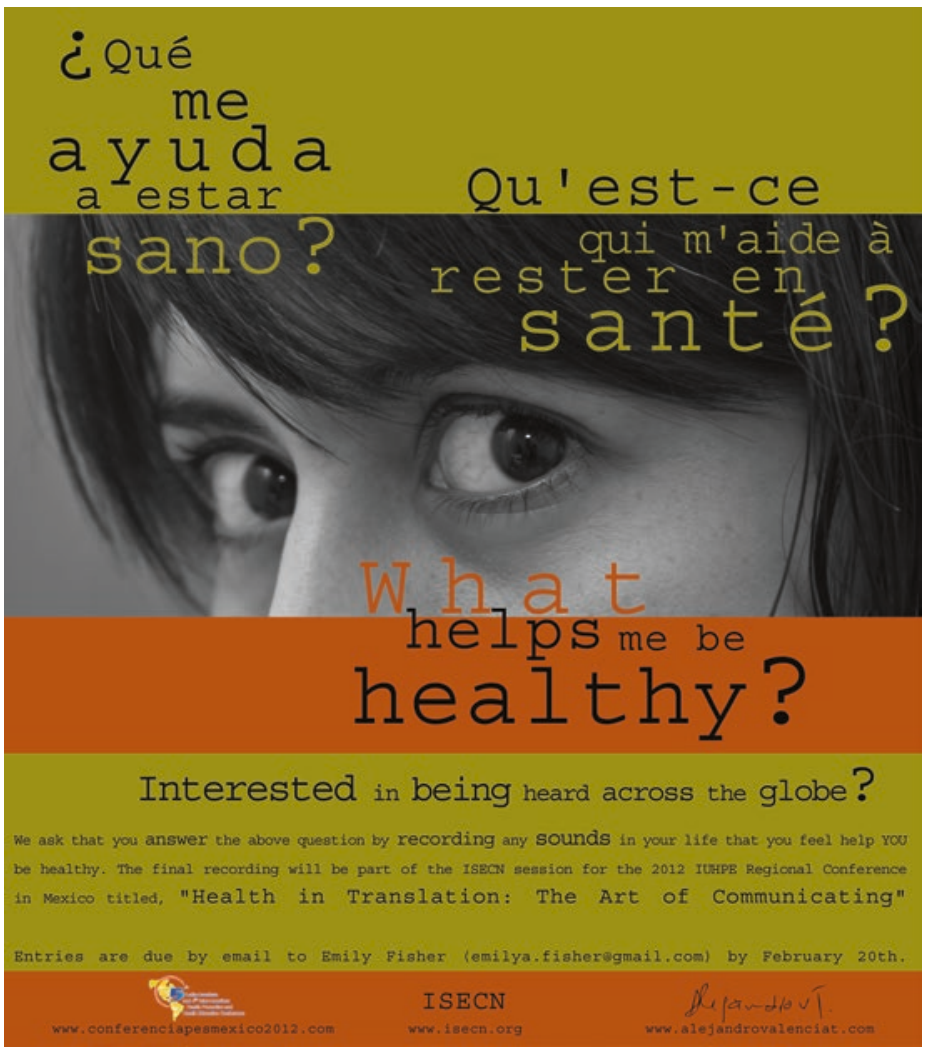

Fig. 20.1 The call for contributions that ISECN sent to members for audio recordings. (Reproduced with permission from ( Alejandro Valencia-Tobón. All rights reserved)

to them (Fig. 20.2). Everyone was working at the same time, and there was conversation, laughter, and joy as participants were able to bring aspects of themselves to the conference space (e.g., aesthetics, tactile engagement, creation) that are almost never given space or voice in a typical session.

The results of this session in Mexico were overwhelmingly positive; it was very well attended and those who came seemed engaged with the various materials. Many people remarked that it was a refreshing break from traditional conference formats. We observed that opting out of using words as the dominant form of communication allowed attendees to connect with others and with global research through visuals, different sensations, and emotions.

\subsubsection{Art as a Tool and a Bridge: Curitiba, Brazil, 2016}

The second arts-based session organized by ISECN was presented at the 22nd IUHPE World Conference in 2016 held in Curitiba, Brazil. Again, a team of ISECN members-a combination of a few who had worked on the conference in Mexico 


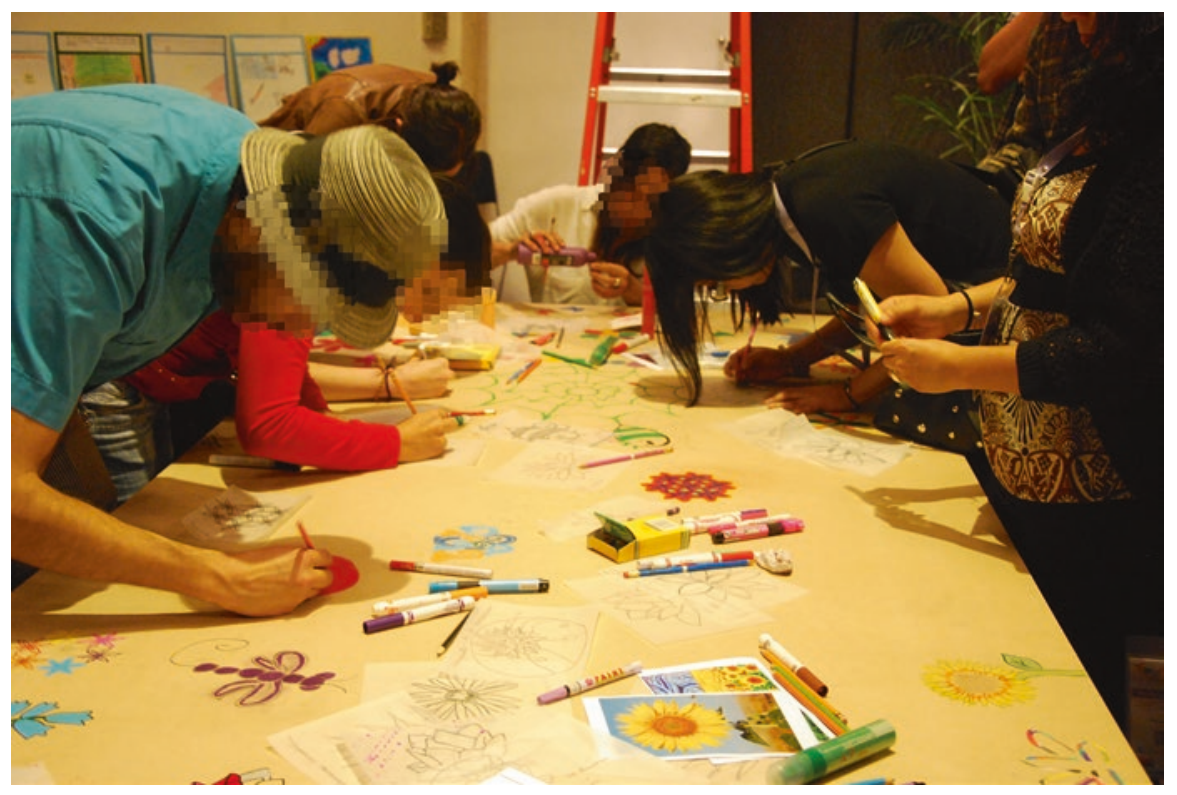

Fig. 20.2 Attendees working on the mural in Mexico City, Mexico

and a few new members - proposed a sub-plenary session, titled "Art as a Tool and Bridge for Health Promotion," which was approved by the IUHPE global scientific committee. Having already gained momentum and experience in utilizing art, we approached the conference in Brazil with excitement and more confidence.

Following the successful model in Mexico, this session again included a gallery walk and a creative activity. As new ISECN members were involved, new arts-based health promotion projects were represented. Visual art pieces were presented along all the walls of the conference room, and session attendees could navigate the space as they wished (Fig. 20.3). Presenters stood by their work and were able to interact with participants and answer questions. This approach encouraged attendees to engage (with presenters and other attendees) through conversation, prioritizing comprehension and dialogue as opposed to the speaker-audience dynamic normalized in conference culture. The gallery included various forms of art including poetry, photography, video, music, and a variety of illustrations (see Table 20.2).

The interactive portion of the session was more informal than the activity in Mexico. We provided diverse raw materials for art projects and provided the following prompt: "Tools help us to build and create. Bridges allow us to go where we could otherwise not go. Before you begin to create, take a moment to close your eyes and think about the tools and bridges that facilitate health promotion." Participants could draw, paint, use mixed media, or create collages (Fig. 20.4). There was then an area to display and view the art created within the session.

Another powerful aspect of the session was the presence of live music. We connected with Brazilian colleagues prior to the conference and arranged to have Kauey Alves Atanascovick Uchoas da Silva sing and play guitar during the entirety of the 


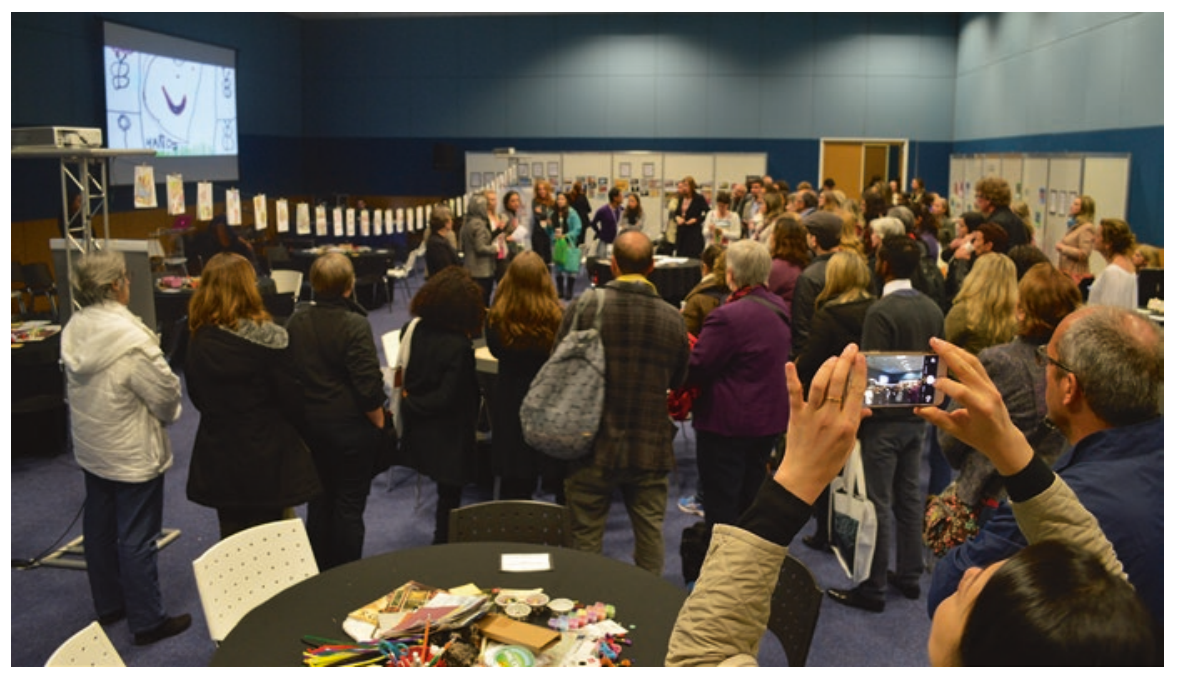

Fig. 20.3 ISECN leadership and presenters welcoming attendees in Curitiba, Brazil

Table 20.2 Arts-based research and practice presented in Curitiba, Brazil

\begin{tabular}{l|l|l|l}
\hline Title/Topic & Art Form & Author & Country \\
\hline $\begin{array}{l}\text { El Camino de Promoción de } \\
\text { Salud: Health \& Wellness as } \\
\text { a Pilgrimage }\end{array}$ & Various visual art media & Erika Bro & USA \\
\hline $\begin{array}{l}\text { Photovoice as a Health } \\
\text { Promotion and Empowerment } \\
\text { Tool }\end{array}$ & $\begin{array}{l}\text { Photos taken by Syrian } \\
\text { refugee youth in a } \\
\text { photovoice study }\end{array}$ & Ozge Karadag Caman & Turkey \\
\hline $\begin{array}{l}\text { Grafitti: Street Voices for } \\
\text { Health Promotion }\end{array}$ & $\begin{array}{l}\text { Graffiti photographic } \\
\text { survey }\end{array}$ & Bianca Palmeri & Brazil \\
\hline $\begin{array}{l}\text { Using Art as a Teaching Tool } \\
\text { in the University Classroom }\end{array}$ & $\begin{array}{l}\text { Various forms of } \\
\text { illustrations }\end{array}$ & $\begin{array}{l}\text { Hope Corbin \& Western } \\
\text { Washington University } \\
\text { Students }\end{array}$ & USA \\
\hline $\begin{array}{l}\text { Lines and Colors to Rethink } \\
\text { the Complexity of Chagas } \\
\text { Disease }\end{array}$ & $\begin{array}{l}\text { Watercolors of the } \\
\text { Argentine illustrator } \\
\text { Carlos Julio Sánchez }\end{array}$ & Mariana Sanmartino & Argentina \\
\hline $\begin{array}{l}\text { Spiritual Health Through } \\
\text { Poetry }\end{array}$ & Poetry & Sara Zarei & Iran \\
\hline $\begin{array}{l}\text { How to Speak About Health } \\
\text { Without Words }\end{array}$ & $\begin{array}{l}\text { Video elaborated with } \\
\text { images taken in Mexico } \\
\text { session in 2012 }\end{array}$ & $\begin{array}{l}\text { ISECN } \\
\text { Edited by Alejandro } \\
\text { Valencia-Tobón } \\
\text { (Colombia) }\end{array}$ & Mexico \\
\hline
\end{tabular}

session. This music created atmosphere and contributed to the general vibe in the room, which was one of openness and inspiration.

The results were, again, astonishing. Both attendees and presenters described the session as passionate, powerful, and transformative. The session also attracted the interest of an academic press who contacted us prior to the session and encouraged us to submit a proposal, laying the groundwork for the volume you now hold in your 
hands (or see on your screen). Indeed, the projects presented in Chaps. 3 and 10 of this volume were presented as part of this sub-plenary session.

\subsubsection{Creative and Participatory Approaches to Promote Planetary Health and Sustainable Development: Rotorua, New Zealand, 2019}

At the 23rd IUHPE World Conference, held in 2019 in Rotorua (New Zealand) and themed "Promoting Planetary Health and Sustainable Development," ISECN led a sub-plenary titled "Creative and Participatory Approaches to Promote Planetary Health and Sustainable Development." As with the previous conferences, the session consisted of a gallery walk showcasing the arts-based presentations followed by an interactive and creation-focused activity. There were diverse arts-based presentations by ISECN members, and invited colleagues shared the creative ways health promotion work was being conducted globally (see Table 20.3).

The interactive portion of the session combined elements from the Mexico and Brazil conferences. We created a "tree" design and invited participants to use pastels to color in the "leaves." We asked attendees to think about the connection between human and planetary health in their drawings. Similar to the mural during the interactive session in Brazil, the individual "leaves" enabled people to introduce their own themes and to work on them for as little or as long as they liked, while the overall impact of combining these individual contributions into a larger image was

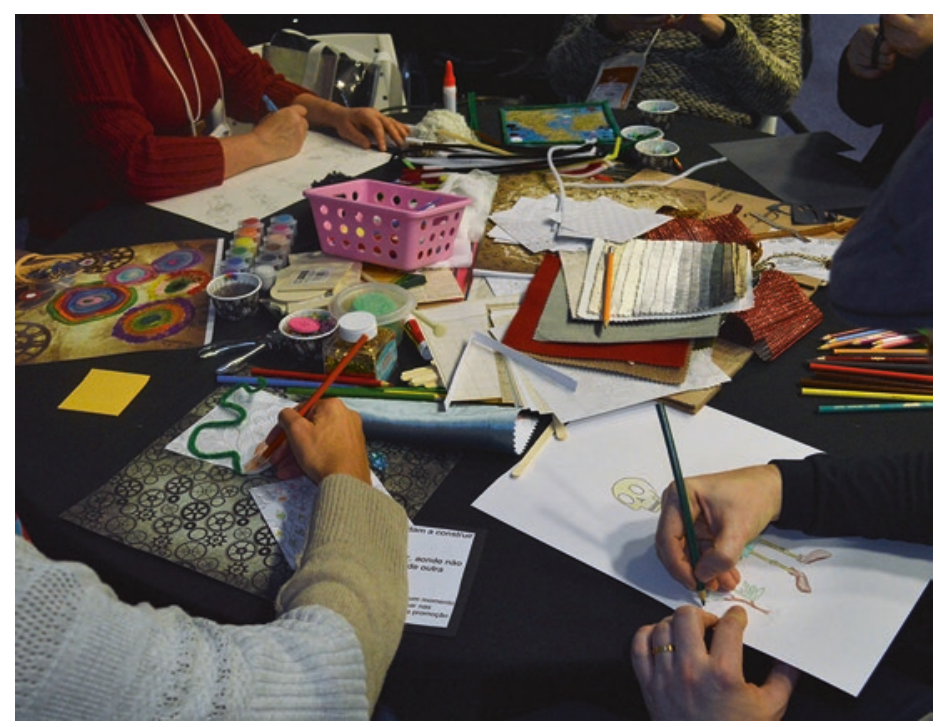

Fig. 20.4 Attendees creating art pieces during the interactive session in Curitiba, Brazil 
Table 20.3 Arts-based research and practice presented in Rotorua, New Zealand

\begin{tabular}{|c|c|c|c|}
\hline Title/Topic & Art & Author & Country \\
\hline $\begin{array}{l}\text { Advocacy Efforts Using Alternate } \\
\text { Media to Address Air Pollution in } \\
\text { Delhi, India }\end{array}$ & $\begin{array}{l}\text { Illustrations \& } \\
\text { PowerPoint } \\
\text { presentation }\end{array}$ & Sridevi Adivi & $\begin{array}{l}\text { United } \\
\text { Arab } \\
\text { Emirates }\end{array}$ \\
\hline $\begin{array}{l}\text { Small-scale Evaluation as a } \\
\text { Participatory Action Research }\end{array}$ & Interactive poster & $\begin{array}{l}\text { Anna Mary } \\
\text { Cooper-Ryan }\end{array}$ & $\begin{array}{l}\text { United } \\
\text { Kingdom }\end{array}$ \\
\hline $\begin{array}{l}\text { Arts-based Mental Health Promotion } \\
\text { Workshop for Indigenous Youth }\end{array}$ & Photography & Sahar Fahnian & Canada \\
\hline $\begin{array}{l}\text { Unlocking Love Film Series: Low- } \\
\text { budget Entertainment Education (EE) } \\
\text { Films for Changing Norms Related to } \\
\text { Gender-based Violence (GBV) in } \\
\text { Timor-Leste }\end{array}$ & Film & $\begin{array}{l}\text { Ba Futuru's Domin } \\
\text { Nakloke } \\
\text { (Organization) }\end{array}$ & $\begin{array}{l}\text { Timor } \\
\text { Liste }\end{array}$ \\
\hline $\begin{array}{l}\text { Student Creativity in a School Food } \\
\text { Intervention in Denmark }\end{array}$ & $\begin{array}{l}\text { Mixed art activities, } \\
\text { including visual } \\
\text { arts and cooking }\end{array}$ & Dorte Ruge & Denmark \\
\hline $\begin{array}{l}\text { What Do You See as the Future of } \\
\text { Health Promotion? }\end{array}$ & Video & ISECN Network & Global \\
\hline
\end{tabular}

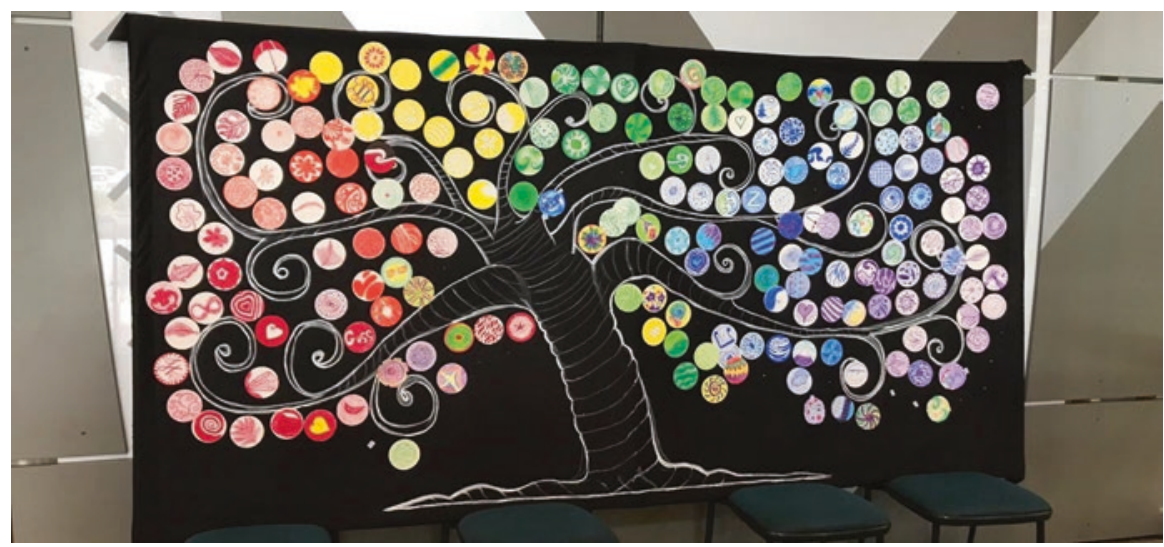

Fig. 20.5 The final product created by session participants at the IUHPE World Conference in Rotorua, New Zealand

reminiscent of the "garden" mural created in Mexico. The resulting tree (Fig. 20.5) was on display in the foyer of the conference hall for the days following the subplenary session and evoked much conversation.

\subsection{Challenges}

While the overall experience of organizing these sessions was overwhelmingly positive, there were a few challenges that we faced, especially as we were implementing a new format within a long-established scientific conference protocol. 


\subsubsection{Advocating for Sessions}

The first challenge had to do with presenting the rationale for the session format in a way that conference program reviewers could understand; this involved careful explanation of the actual session logistics and needs as well as why such an approach would add value to the conference. Because the sessions are very different from typical conference sessions, and the typical conference submission portals do not allow for the deviations that we were proposing, we had to provide extra information and detail outside of the formal submission opportunity and even answer specific questions from the scientific review committee. At times it was difficult for individuals on the scientific committee to understand the idea, and this required additional work on our end to ensure the sessions happened and that we were given appropriate space. In more recent years, we were fortunate to have internal advocacy efforts because some committee members had experienced the Mexico session and could attest to its value for future conferences.

\subsubsection{Room Requirements and Extensive Set-up}

Given the need to hang images, posters, and other materials, our sessions had unique space requirements. We needed, for example, to be able to use blue tape or pins or blue tack to post the various exhibits on the walls. We had to get special permission for these, at times. Set-up also required a significant amount of additional supplies and time. We would often have to talk with the conference organizers about when we would be able to access the room, requesting that the session be scheduled for the first morning slot or immediately following lunch. We had to organize a crew of volunteers to get the room ready for the session and to help with breakdown after the session. Depending on the interactive project, we also had to find funding for art supplies and find ways to bring these supplies and any pre-made projects to the conference location.

\subsubsection{Attendance Complications}

From an equity perspective, we sought to include anyone with relevant work regardless of their ability to appear in person at the conference because our members often lacked funding to attend the conference. For some conferences, bursaries were available; for others, there were no funds. For these and other reasons, many of our presenters had to send their materials, and we presented them on their behalf. In New Zealand, however, a last-minute change by the organizers required that unregistered participants have their names removed from the program, which led to a few ISECN members withdrawing their contributions. 


\subsection{Brief Reflections}

For centuries, art has been used as a vehicle to express meaning and articulate ideas. The act of doing so is not only effective but also an act of activism within learning. Richardson and Ricketts (2017) reviewed the use of art at an education conference and argued that it moved participants “... away from traditional vertical hierarchies of knowledge dissemination towards more lateral exchanges and emergent learning structures” (p. 168). These new "exchanges" and "structures" (Richardson and Ricketts 2017) disrupted traditional flows of knowledge sharing and introduced new paths of understanding to the human mind. While challenging the power dynamics and norms within education is significant, the use of art simultaneously enhances the meaning of the content being explored.

The purpose of attending conferences, especially global conferences, is to network with professionals, share ideas and knowledge, and connect to evolve the field. The idea is to leave with more than you came with. Art is a potential bridge for this purpose while, simultaneously, working to dismantle the hierarchy of formal education and the monoculture of scientific knowledge (de Sousa Santos 2012). Artsbased activities can facilitate the equalizing of knowledge and world-views by relinquishing notions of "right" and "wrong" and by creating space for a diversity of ideas and artistic expression (Williams 2002).

By engaging in artistic expression, participants are able to share their knowledge as well as reflect on the creation of others. Participants can choose to share their perspectives or allow for others to reflect through their own process (Williams 2002). Art purposefully demolishes the boundaries of verbal communication while enhancing meaning and showcasing the diverse answers individuals can have to the same question. From our experience, the level of relevance this has to the purpose of international conferences is astounding. Whether the goal is to transcend language barriers, enhance shared meaning, or bring fun to learning, art is a powerful strategy. However, disrupting conference norms in this way, while powerful, takes additional effort and strategizing. Thus, we hope that sharing our multiple experiences in this process will enable others to both understand the value of this work and to improve the ability to plan accordingly.

Acknowledgements The authors would like to recognize the contributions of the following conference session organizers: Erika Bro, Mackenzie Foster, Sharon Ortiz, Bianca Palmeri, Sara Rodgers, Kauey Alves Atanascovick Uchoas da Silva, and Ankur Singh. We would also like to thank Erma Manoncourt, Suzanne Jackson, Ann Pederson, and Robyn Perlstein for their encouragement, support, and help setting up and taking down.

\section{References}

Chilisa, B. (2005). Educational research within postcolonial Africa: A critique of HIV/AIDS research in Botswana. International Journal of Qualitative Studies in Education, 18(6), 659-684. https://doi.org/10.1080/09518390500298170.

Corbin, J. H., Fisher, E. A., \& Bull, T. (2012). The International Union for Health Promotion and Education (IUHPE) Student and Early Career Network (ISECN): A case illustrating three strategies for maximizing synergy in professional collaboration. Global Health Promotion. https:// doi.org/10.1177/1757975912441232. 
de Sousa Santos, B. (2012). Public sphere and epistemologies of the South. Africa Development, XXXVII (1), 43-67.

de Sousa Santos, B. (2016). Epistemologies of the South: Justice against epistemicide. New York: Routledge.

Eernstman, N., Van Boeckel, J., Sacks, S., \& Myers, M. (2012). Inviting the unforeseen: A dialogue about art, learning and sustainability. In Learning for sustainability in times of accelerating change (pp. 201-212). Wageningen: Wageningen Academic Publishers.

Fox, A., Gillis, D., Anderson, B., \& Lordly, D. (2016). Stronger together: Use of storytelling at a dietetics conference to promote professional collaboration. Canadian Journal of Dietetic Practice and Research, 78(1), 32-36. https://doi.org/10.3148/cjdpr-2016-027.

Freire, P. (1970). Pedagogy of the oppressed. New York: Herder and Herder.

Graham, G. (1995). Learning from art. The British Journal of Aesthetics, 35(1), 26-37.

Nguyen, M., Miranda, J., Lapum, J., \& Donald, F. (2016). Arts-based learning: A new approach to nursing education using andragogy. Journal of Nursing Education, 55(7), 407-410. https://doi. org/10.3928/01484834-20160615-10.

Richardson, P., \& Ricketts, K. (2017). Review of "arts-based contemplative practices in education": 2017 Canadian Society for Studies in Education ARTS Pre-conference. Art/Research International: A Transdisciplinary Journal, 2(2), 168-175. https://doi.org/10.18432/R2S91K.

SciConf. (2019). The Scientific Conference-Department of History of Science and IdeasUppsala University, Sweden. https://www.idehist.uu.se/forskning/forskningsprojekt/the-scientific-conference/. Accessed 18 Feb 2020.

Simkhada, P., Teijlingen, E. V., Hundley, V., \& Simkhada, B. D. (2013). Writing an abstract for a scientific conference. Kathmandu University Medical Journal, 11(3), 262-265. https://doi. org/10.3126/kumj.v11i3.12518.

Tikly, L. (2004). Education and the new imperialism. Comparative Education, 40(2), 173-198. https://doi.org/10.1080/0305006042000231347.

Varsavsky, O. (1969). Ciencia, política y cientificismo. Capital Intelectual S. A.

Williams, B. (2002). Using collage art work as a common medium for communication in interprofessional workshops. Journal of Interprofessional Care, 16(1), 53-58. https://doi. org/10.1080/13561820220104168.

World Health Organization. (1986). The Ottawa Charter for Health Promotion. https://www.who. int/healthpromotion/conferences/previous/ottawa/en/. Accessed 20 Feb 2020.

Zimmer, B., Carson, C. E., \& Horn, L. R. (2011). Among the new words. American Speech, 86(3), 355-376. https://doi.org/10.1215/00031283-1503937.

Open Access This chapter is licensed under the terms of the Creative Commons AttributionNonCommercial-NoDerivatives 4.0 International License (http://creativecommons.org/licenses/ by-nc-nd/4.0/), which permits any noncommercial use, sharing, distribution and reproduction in any medium or format, as long as you give appropriate credit to the original author(s) and the source, provide a link to the Creative Commons license and indicate if you modified the licensed material. You do not have permission under this license to share adapted material derived from this chapter or parts of it.

The images or other third party material in this chapter are included in the chapter's Creative Commons license, unless indicated otherwise in a credit line to the material. If material is not included in the chapter's Creative Commons license and your intended use is not permitted by statutory regulation or exceeds the permitted use, you will need to obtain permission directly from the copyright holder. 